EXEMPLARIA Classica

Journal of Classical Philology

18, 2014, pp. 29-46

ISSN 1699-3225

\title{
EL EXTRANJERO DE ELEA Y LA "SOFÍSTICA DE NOBLE LINAJE” (PLATÓN, SOFISTA 230 E5-231 B8)*
}

\author{
Miguel Ángel SPINASSI \\ Universidad Nacional de Córdoba \\ maspinassi_uni.cba@hotmail.com
}

\section{SUMMARY}

The following paper deals with the famous passage of Sophist 230e5-231b8. My basic assumption holds that the sophist would not be the one who appears in the sixth definition as the practitioner of elenchus, but the true philosopher, represented in the dialogue by the figure of the Eleatic Stranger.

KEYWORDS

Sophistry, Noble Lineage, Philosophy.
RESUMEN

El siguiente artículo tiene que ver con el famoso pasaje de Sofista 230e5-231b8. Mi hipótesis fundamental sostiene que no sería el sofista quien aparece en la sexta definición como practicante del élenkhos, sino el verdadero filósofo, representado en el diálogo por la figura del Extranjero de Elea.

Palabras Clave

Sofística, noble linaje, filosofía.

Fecha de recepción: 06/08/2013

Fecha de aceptación y versión final: 05/02/2014

En el sexto intento por definir al sofista, el anónimo Extranjero de Elea arriba a la descripción del عُ $\lambda \varepsilon \gamma \chi$ oc como arte que purifica el alma de su vana presunción de saber. A la hora de decidirse por la identidad de sus practicantes, si bien se muestra en un principio temeroso de llamarlos "sofistas", sin embargo está de acuerdo con que sean ellos, de momento, los que se sirven de aquel método de purificación que termina llamando "sofística de noble linaje”. El objetivo de este artículo es arrojar cierta luz sobre el problema de la verdadera identidad de estos practicantes, aclarando, en la medida de lo

* Quisiera agradecer aquí a la profesora Dra. Zina Giannopoulou, de la Universidad de California, Irvine, por su amabilidad y buena disposición a la hora de facilitarme el acceso a su artículo sobre el Sofista de Platón. Agradezco también las muy valiosas observaciones y críticas que los revisores de Exemplaria Classica hicieron sobre una versión preliminar de este artículo. De cualquier error que aún persista, soy el único responsable. 
posible, el sentido del ambiguo pasaje de 230e5-231b8, que ha sido objeto de mucha controversia entre los estudiosos y comentaristas del diálogo. Mi argumento principal sostiene que allí no sería el sofista quien está en la mente del Eleata, sino el filósofo y su manejo noble del lógos. Para apoyar esta interpretación me concentraré especialmente en la figura de este extranjero perteneciente al círculo de Parménides y Zenón, en la manera en la que viene presentado por Platón como verdadero filósofo, poniendo de relieve algunos indicios del texto que, a mi juicio, nos permitirían asociar su desempeño en toda la conversación con aquel procedimiento de purificación que él mismo describe. Si mi lectura del texto es correcta, creo que en su trato y manejo del lógos, el Eleata podría ser identificado con una versión "mejorada" del sofista, a saber, con uno de "noble linaje", que para Platón no sería otra cosa más que el verdadero filósofo.

Por cierto, muchos no han visto en la sexta definición más que el propio accionar de Sócrates según leemos en los diálogos tempranos. Sin entrar más allá en esta cuestión, personalmente, creo que una interpretación tal no está equivocada, ya que Sócrates, a los ojos de Platón, sería un "sofista noble" y practicaría también él un método de purificación. Ahora bien, por alguna razón que en el diálogo no se explicita, Sócrates cede su lugar ante un anónimo extranjero quien termina asumiendo el rol más importante como interlocutor principal y guía de la conversación ${ }^{1}$. En este sentido, la lectura que presento intenta mostrar el carácter autorreferencial de las palabras del Extranjero en la sexta definición, cómo es que lo dicho allí se vería reflejado de alguna manera a lo largo de todo el diálogo en su propio accionar con el lógos.

$\mathrm{Y}$ bien, ante todo, me parece conveniente presentar el texto griego y traducción de la parte final de la sexta definición que comienza precisamente con la pregunta por la identidad de los practicantes. Luego, propondré una lectura casi línea por línea, deteniéndome especialmente en tres puntos fundamentales que darían pie para suponer o, al menos, sospechar la presencia del filósofo allí donde uno espera al sofista. Ahora bien, me gustaría llamar la atención sobre un aspecto que sin dudas condiciona la lectura de todo el texto $\mathrm{y}$ ha contribuido ciertamente al hecho de que los intérpretes y comentaristas del diálogo, aún hoy, continúen discutiendo sobre la correcta interpretación del mismo. Hago referencia a la notable ambigüedad de todo el pasaje ${ }^{2}$, ambigüedad que Platón busca, según creo, deliberadamente para

${ }^{1}$ La cuestión no sería, como creo, saber si es uno o el otro "el sofista de noble linaje", sino por qué ahora lo es uno y no el otro. Avanzar una hipótesis al respecto, demandaría un esfuerzo extra de interpretación que a fin de cuentas no influiría del todo en la lectura que aquí propongo: tanto Sócrates como el anónimo de Elea comparten, a mi juicio, el hecho de ser “verdaderos filósofos”, purificadores del alma. De todos modos, algunas palabras diré al respecto en la conclusión de este trabajo.

${ }^{2}$ Cf. Z. Giannopoulou, “'The Sophistry of Noble Lineage' Revisited: Plato's Sophist 226b1231b8”, ICS 26, 2001, 114. En lo que sigue, tendré en cuenta el texto griego de la edición crítica 
suscitar también en su lector la duda y confusión, a tal punto que uno llega a preguntarse "¿De quién se está hablando en realidad? ¿No es el sofista el objeto de la investigación?”. Me atrevería a decir que no sólo quienes toman parte en la conversación -el Extranjero de Elea, el joven Teeteto y todo el grupo de amigos que oye- se encuentran en dificultades al momento de decir quiénes son los practicantes del ع̌ $\lambda \varepsilon \gamma X \mathrm{Oc}^{3}$, sino que también nosotros, lectores modernos de Platón, nos encontramos en una situación semejante. Y es probable que ello tenga que ver con una de las primeras afirmaciones que se hacen al inicio mismo del diálogo sobre la persona del filósofo y que dejan por sentado ya uno de los motivos vertebradores de toda la conversación: la distinción de géneros. Leemos, en efecto, que muchas veces, "debido a la ignorancia de la mayoría, el verdadero filósofo -y no quien finge serlose aparece como un sofista, como un político o incluso como uno que está completamente loco"4. Sobre la base de estas palabras de Sócrates, que son como una advertencia a estar atentos, parecería como si Platón quisiera poner a prueba también la capacidad de su lector de distinguir al auténtico filósofo del sofista y de no confundirlos más allá de sus semejanzas. Frente a esta situación, pues, uno tiene que abrir bien los ojos, lo mismo que Teeteto, para no dejarse engañar.

Dicho esto, vayamos ahora al texto fundamental. El diálogo entre el Extranjero y Teeteto (Sph. 230e5-231b8) dice aproximadamente así:

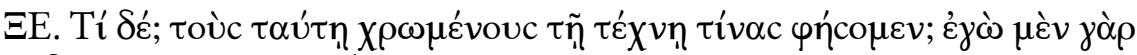

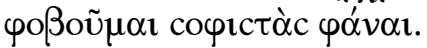

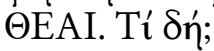

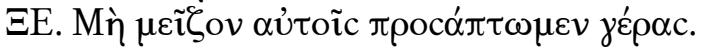

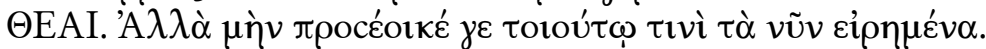

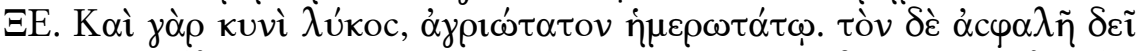

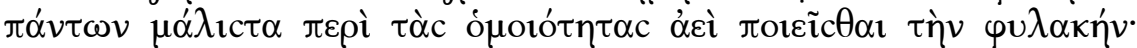

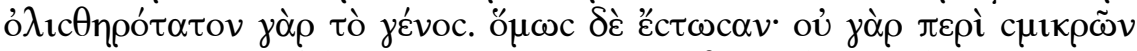

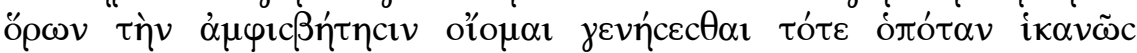

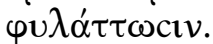

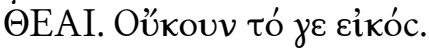

"Extr. ¿Y entonces qué? ¿Quiénes afirmaremos que son los que se sirven de este arte? Yo, personalmente, temo afirmar que son sofistas...

de J. Burnet, Platonis Opera, vol. 1, Oxford 1900. Las traducciones son mías y las referencias que en cada caso no especifiquen el nombre del diálogo pertenecen al Sofista.

${ }^{3}$ Esto se ajusta mejor a la persona del joven Teeteto que a la del Extranjero, quien, a mi juicio, sabe y puede dirimir la cuestión pero voluntariamente no lo hace.

${ }^{4} \mathrm{Pl}$. Sph. 216c2-d2. Con relación a este pasaje se puede leer aquel de 254a8-b1, en donde se dice que la mayoría de las personas son incapaces de contemplar "lo divino" con los ojos del alma. 
Teet. Pero ¿por qué?

Extr. Para no concederles un honor más grande.

Teet. Pero lo que acabamos de decir ahora parece adecuarse a éste (sc. al sofista).

Extr. Sí, como así también al perro se parece el lobo, lo más salvaje a lo más manso. Un hombre seguro tiene que estar siempre atento y más aún cuando se trata de semejanzas: el del 'sofista' es uno de los géneros más escurridizos. De todos modos dejemos que sean ellos. Creo, pues, que no habrá ninguna duda con respecto a límites tan finos, cuando uno esté lo suficientemente prevenido.

Teet. Y bien, parece que no".

\section{EL HONOR DE LA FILOSOFÍA}

Al inicio de nuestro pasaje, el Eleata manifiesta claramente su temor de afirmar que son sofistas los practicantes del método de la purificación. Él mismo explica el porqué: "para no concederles un honor más grande" $(\mu \varepsilon \tilde{i} \zeta o v$

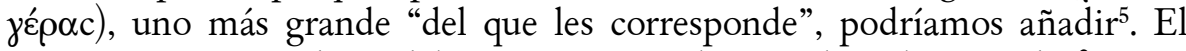
Extranjero ve que las palabras que en 230b4-e4 describieron al है $\lambda \varepsilon \gamma X O c$ como "la más grande y soberana de todas las purificaciones" no se ajustan ahora a la persona ni al quehacer de un sofista. Como lo advirtió N. Notomi, la sexta definición desarrolla algunos "elementos positivos" de la sofística ${ }^{6}$ y este cambio o "mejoramiento" del sofista no debería ser desatendido: a mi modo de ver, el temor del Eleata podría entenderse mejor, si se lo considera en un contexto de "defensa" del honor y estima de la filosofía. Esta тı de alguna manera está reflejada en el término yépoc, se manifestó por primera vez al inicio del diálogo, cuando se decía que los verdaderos filósofos eran "poco estimables" para algunos, pero "dignos de la mayor estima" para otros

${ }^{5}$ G. B. Kerferd, "Plato's Noble Art of Sophistry (Sophist 226a-231b)", CQ 4.1-2, 1954, 84-5, apoyándose en la interpretación de los primeros comentaristas del diálogo, señaló acertadamente

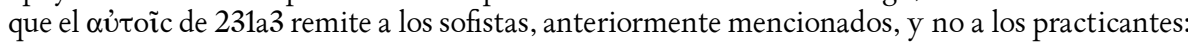
"...the people to whom the Stranger is afraid of ascribing too much honour are the sophists, and what he is saying is that the function of cathartic teaching is too high an honour to be assigned to the sort of people described in the previous five definitions of the sophist". De la misma opinión es J. R. Trevaskis, "The Sophistry of Noble Lineage (Plato, "Sophistes 230a5232b9”)", Phronesis 1, 1955, 37; R. S. Bluck, Plato's Sophist: A Commentary, Manchester 1975, 42; G. Movia, Apparenze, essere e verità. Commentario storico-filosofico al "Sofista" di Platone, Milano 1991, 171-2; N. Notomi, The Unity of Plato's Sophist: Between the Sophist and the Philosopher, Cambridge 1999, 65; Giannopoulou, "The Sophistry", 115, entre otros. Distintamente lo entienden F. M. Cornford, Plato's Theory of Knowledge, the Theaetetus and the Sophist of Plato translated with a running commentary, London 1935, 180 n. 2 y A. E. Taylor, Plato. The Sophist and the Statesman, Folkestone-London 1961, 115.

${ }^{6}$ Notomi, The Unity, 65. Adviértase en este sentido el uso reiterado de superlativos en

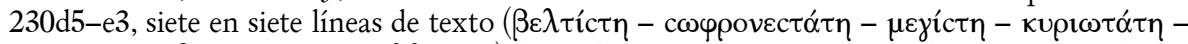

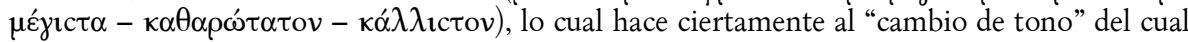
habla Cornford, Plato's Theory of Knowledge, 177. 


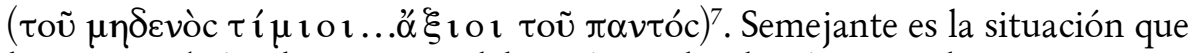
leemos también al comienzo del Político, donde Sócrates advierte un error de "cálculo" en Teodoro, quien colocó al sofista, al político y al filósofo en

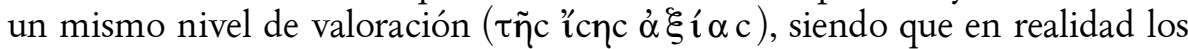
tres se diferencian entre sí por la estima $(\tau \tilde{\eta} \tau \mathbf{\imath} \mu \tilde{\eta})$ que tenemos de ellos: para Sócrates el filósofo supera en "valor" a sus contrincantes y tiene que ser tratado, como se merece, después de aquellos ${ }^{8}$. A la luz de estas declaraciones, uno podría pensar entonces que el Extranjero querría ser parte de los que estiman la verdadera filosofía ${ }^{9}$ y no la deshonran, como habría sido el caso, si hubiera aceptado sin más a los sofistas como practicantes de la noble tarea de purificar el alma. Es cierto, éstos reciben el honor de ser los practicantes del

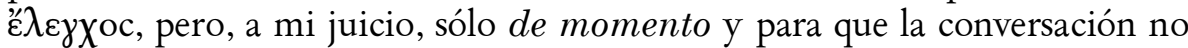
sea demorada y se pueda avanzar en la investigación.

Que el Eleata con su actitud de salvaguardar el honor de la filosofía estaría mostrándose como verdadero filósofo, encuentra un interesante apoyo en el pasaje de República 539c-d, en donde Sócrates, hablando de la edad apropiada para iniciarse en el ejercicio de la dialéctica, afirma que lo mejor sería practicarla en la madurez, puesto que el hombre maduro ya no se ve atrapado por esa manía que tienen los jóvenes de refutar, sino que evita el "contradecir" por mera diversión $(\pi \alpha \imath \delta i \tilde{\alpha} c \chi \alpha \alpha \rho \imath v)$ y hace el esfuerzo por imitar a quien persigue el diálogo como camino para descubrir la verdad. Al hacer esto,

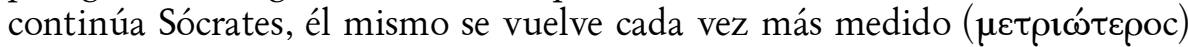
y logra que su ocupación, la filosofía, deje de ser desestimada ante los demás

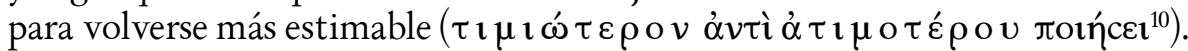
Y en la escena introductoria del Sofista, cuando Sócrates se pregunta si el Extranjero en realidad no es un dios de la refutación, uno que viene a ponerlos a prueba y a evidenciar la impericia con la que se mueven en los discursos, Teodoro responde que ésa no es la forma de ser del Eleata, sino que, por el contrario, él se muestra mucho "más medido que aquellos que se afanan en

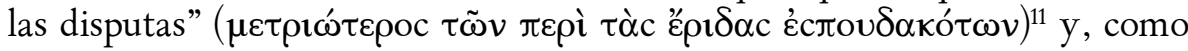

7 Pl. Sph. 216c6-8. Madvig, según anota Burnet, excluyó tínıo del texto, quizás por

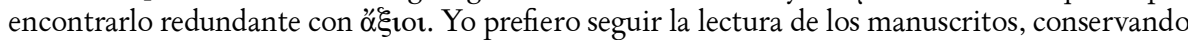
el quiasmo de la expresión.

${ }^{8} \mathrm{Pl}$. Plt. 257a1-b4. Para la cuestión de la promesa platónica de un tratamiento por escrito del Filósofo, véase Giannopoulou, "The Sophistry”, 101 n. 1., pero fundamentalmente la opinión de G. Reale, Per una nuova interpretazione di Platone. Rilettura della metafisica dei grandi dialoghi alla luce delle «Dottrine non scritte», Milano 1995, 421 ss., como así también Movia, Apparenze, 48 y los trabajos de Th. A. Szlezák, Leer a Platón, Madrid 1997, 96 ss. y Das Bild des Dialektikers in Platons späten Dialogen, Berlin-New York 2004, 158-60.

${ }^{9}$ Véase, por ejemplo, el texto de $S p h .249$ c10: "para quien es filósofo y estima en sumo

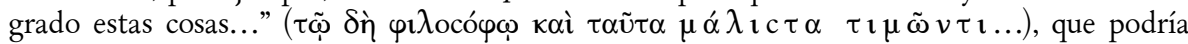
entenderse como una autorreferencia del propio Eleata.

${ }^{10}$ Cf. también Tht. 168b.

${ }^{11} \mathrm{Pl}$. Sph 216b8. Entiendo las "disputas” como "disputas verbales” y pienso en los sofistas 
vemos más adelante, el Extranjero se toma bien en serio la actual discusión con Teeteto y sus preguntas no persiguen la disputa verbal ni tampoco el

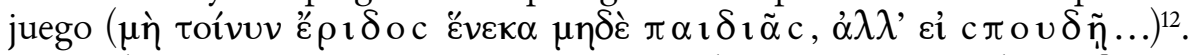
Teniendo en cuenta esto, uno estaría en condiciones entonces de confirmar lo primero que se nos dijo del Eleata al inicio del diálogo: este amigo del círculo de Parménides y Zenón es "todo un filósofo" (216a4: $\mu \alpha \dot{\lambda} \lambda \alpha \delta$ غ̇ ơ $v \delta \rho \alpha$

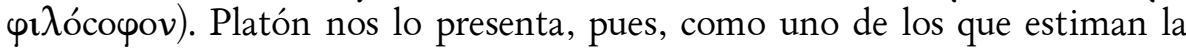
verdadera filosofía y sólo desde esta perspectiva cobraría perfecto sentido su temor de atribuir a los sofistas la noble tarea de purificar el alma.

\section{LA MANSEDUMBRE COMO CUALIDAD PROPIA DEL FILÓSOFO}

El joven Teeteto, por su parte, parece no comprender aún por qué el Eleata concedería a los sofistas un honor más grande del que les conviene. Él no reconoce allí otra cosa más que al sofista y su proceder con el lógos. Es más, para Teeteto todo lo dicho hasta el momento se asemeja mucho a la presa que persiguen ${ }^{13}$. Sin embargo, como lo advierte el Extranjero, también se da el mismo parecido o semejanza entre el lobo y el perro, animales que, a pesar de ser similares entre sí, representan "polos opuestos" en la escala que

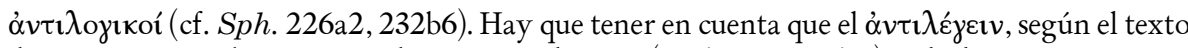
de República arriba mencionado, provoca "locura" (R. 539c6: $\mu \alpha v i ́ \alpha c)$ y el Eleata precisamente

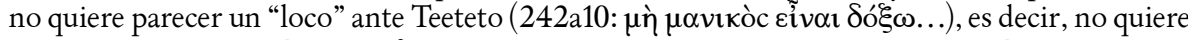
ser considerado un sofista ò $\nu \tau \imath \lambda$ oyıkóc. Recuérdese además que los verdaderos filósofos, según vimos, suelen ser tenidos por la mayoría como unos que están "completamente locos" $(216 \mathrm{~d} 2$ :

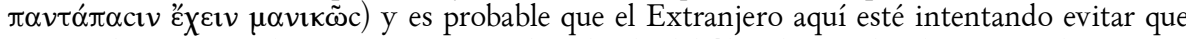
Teeteto forme parte de esa mayoría. Para lo ridículo del filósofo ante los demás, puede verse $R$. 517a2 y Tht. 173c7-175e5.

${ }_{12} \mathrm{Pl}$. Sph. 237b10. En este momento del diálogo, el Extranjero discute con Teeteto una

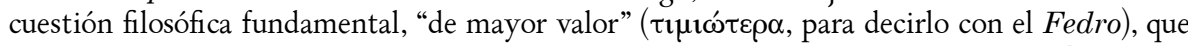
tiene que ver con el Ser y el No-Ser. En esto, él se muestra también como verdadero filósofo en tanto trata con seriedad lo que tiene que ser tratado seriamente, separando la simple contienda verbal de la discusión dialéctica (véase Sph. 259b8-c5). Como se dice en Teeteto 167e3-168a2, en las disputas verbales se suele bromear $(\pi \alpha i \xi \eta)$ y se busca confundir al interlocutor, mientras

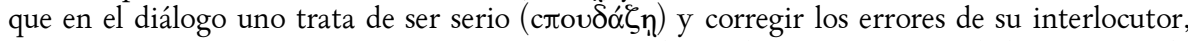
sin cometer injusticia con sus argumentos. Para el par de opuestos "seriedad-juego" en la interpretación de los diálogos y su relación con el concepto platónico de "filósofo", véase Th. A. Szlezák, Platon und die Schriftlichkeit der Philosophie, Berlin-New York 1985, 12-5, passim.

${ }^{13}$ Cuando Bluck, Plato's Sophist, 43, escribe: "Yet if the description of Socrates' method only, and the distinctions between him and the sophists are such that they are 'poles apart', it is exceedingly difficult to understand why Theaetetus regards the account of Socrates' method as resembling that of the Sophist (231a)", parece no tener en cuenta que la advertencia del Extranjero de "montar guardia ante las semejanzas", como veremos más adelante, va dirigida especialmente al joven Teeteto, que aún no maneja suficientemente la cuestión de la ó $\mu_{0}$ ótnc. De acuerdo con Fedro 273d5, sólo quien conoce la verdad -el filósofo- sabe encontrar las semejanzas de la mejor manera y Teeteto, en este sentido, es un aprendiz que está en camino de ser un verdadero filósofo, pero que aún no lo es. Para este motivo, cf. Szlezák, Das Bild, 135-8. 
va de lo más manso a lo más salvaje $e^{14}$. Pero ¿qué sentido tienen aquí estas palabras y a qué viene la mención del lobo y el perro? En primer lugar,

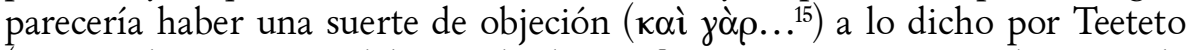
(sc. que el practicante del método de purificación parece encajar bien con la persona del sofista), pero al mismo tiempo una advertencia a estar atentos y no dejarse engañar por las semejanzas, como si el Extranjero dijera: "sí, está bien, Teeteto. El sofista se parece al practicante, pero también el lobo se parece al perro, el animal más salvaje al más manso, así que ten cuidado con sus parecidos". El hecho de que Platón, entre tantos otros ejemplos posibles, haya elegido la pareja "perro-lobo" y sus características esenciales de "manso-salvaje" para dar cuenta de este problema de las semejanzas, debería llamarnos la atención. Quien oye aquí la mención de este "perro manso" no puede evitar pensar en aquel "perro filósofo" de la República ${ }^{16}$. A mi modo de ver, éste sería otro indicio de la presencia del filósofo en la búsqueda del sofista. En efecto, en los diálogos platónicos vemos a menudo lo "manso" en íntima relación con el ámbito de la filosofía, mientras que lo "salvaje" suele ser presentado como característica propia del no-filósofo. Tanto un aspecto como el otro se encuentran estrechamente ligados a la problemática de la educación -precisamente el motivo central de la sexta definición- y así como la domesticación hace que un animal salvaje se amanse, de la misma manera actúa la educación en el hombre, amansándolo. En República 410e, por ejemplo, se dice que la naturaleza filosófica tiene algo manso ( $\tau$ ò

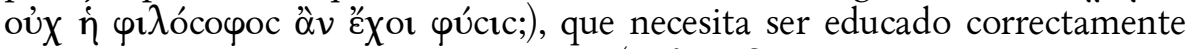

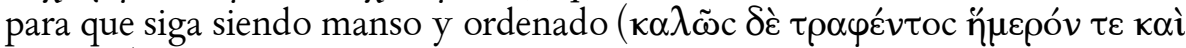
кócuıov) y no se ablande más de lo debido ${ }^{17}$. Casi en los mismos términos se expresa en las Leyes el Ateniense, al decir que el hombre, naturalmente

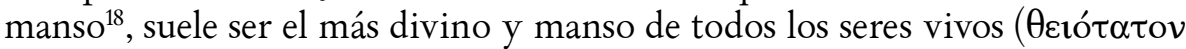

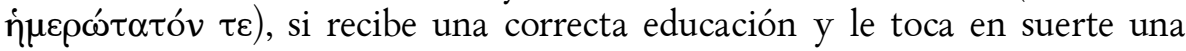
naturaleza apropiada, pero que, por el contrario, si no es educado de una

${ }^{14}$ Así Trevaskis, "The Sophistry of Noble Lineage", 38: "Plato is apparently saying that although wolf and dog resemble each other, they are at extremes of savageness and tameness. Their superficial resemblance disguises their real natures which are poles apart".

${ }^{15}$ Cf. J. D. Denniston, The Greek Particles, Oxford 1954, 109-10.

${ }^{16}$ Pl. R. 375a-376c. Cf. Kerferd, "Plato's Noble Art”, 85, y Movia, Apparenze, 172-3. Yo no iría tan lejos en la interpretación como Cornford, Plato's Theory of Knowledge, 182 n. 1, para quien Platón tendría en mente en este pasaje del Sofista a los guardianes de la República. Tampoco descartaría, como Trevaskis, "The Sophistry of Noble Lineage", 38 n. 1, la posibilidad de que las dos menciones de lo "manso" en $230 \mathrm{~b} 9$ y $231 \mathrm{a} 6$ tengan que ver con el (perro) "filósofo" de la República.

${ }^{17}$ Para otros contextos de la "mansedumbre" asociada con la filosofía, véase $R$. 416c2: los guardianes del Estado, filósofos, son mansos; 486b11: el alma mansa del filósofo y la salvaje del que no lo es; 591b: el alma de quien es castigado se ablanda y se vuelve más mansa; 620d5: los injustos asociados a animales salvajes y los justos a animales mansos y también Grg. 516c3 ss.: los justos son mansos, etc.

${ }^{18}$ Cf. también $S p h .222$ b7 ss. 


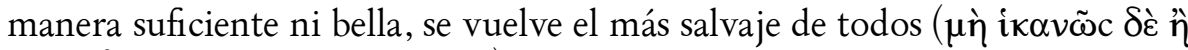

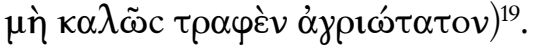

Desde esta perspectiva, cuando leemos la descripción del método de purificación en $230 \mathrm{~b} 4$ ss., un punto nos llama especialmente la atención: quienes han sido puestos a prueba en la refutación, afirma el Extranjero, después de ver que sus opiniones se han manifestado como contradictorias entre sí, terminan irritándose consigo mismos y amansándose para con los

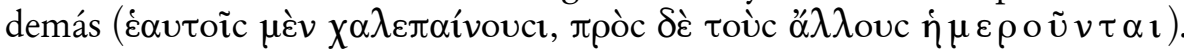
Teniendo en cuenta otros pasajes de los diálogos, ésta parecería ser una situación "ideal" ${ }^{20}$, que no le sorprende tanto a Teeteto como uno podría esperar. Que el amansarse frente a los demás, después de haber sido sometido

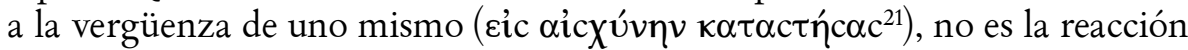
más común o frecuente en una situación de diálogo, lo muestra claramente Sócrates en el relato de la Apología, al afirmar que aquellos que eran refutados por sus fanáticos imitadores, no se enojaban consigo mismos sino con el

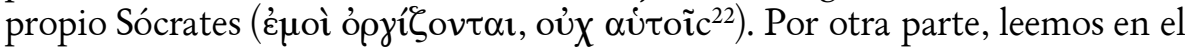
Gorgias que la mayoría de las veces quienes intervienen en una conversación terminan disolviendo el diálogo al irritarse ( $\chi \alpha \lambda \varepsilon \pi \alpha i ́ v o v c t)$ unos con otros, porque creen que aquello que se les dice, por ejemplo, cuando uno afirma que el otro no habla con la verdad, es por envidia o por mero afán de vencer en la discusión ${ }^{23}$. El gusto que experimenta Sócrates al refutar, pero principalmente al ser refutado por otro ${ }^{24}$, nos habla de su carácter manso, de su buena disposición hacia su interlocutor que facilita el normal desarrollo de la conversación. Tal actitud, que lo diferencia de aquellos que se irritan, no consigo mismos, sino con los demás, es la misma que refiere el Eleata y constituye, a mi juicio, una actitud propiamente filosófica que Platón parece exigir en sus diálogos una y otra vez como condición indispensable para dar el primer paso, uno bien sólido ${ }^{25}$, en la búsqueda de la verdad: reconocer que uno sabe sólo lo que sabe y nada más que eso.

${ }^{19} \mathrm{Pl}$. Lg. 766a ss.

${ }^{20}$ Cf. W. K. C. Guthrie, A History of Greek Philosophy IV, Cambridge 1978, 129.

${ }^{21}$ Pl. Sph. $230 \mathrm{~d} 1$.

$22 \mathrm{Pl}$. Ap. $23 \mathrm{c} 8$.

${ }^{23}$ Pl. Grg. 457c4-d5. Cf. también Phd. 91a3.

${ }^{24}$ Esta preferencia que tiene Sócrates por "el dejarse refutar", que considera un bien mayor

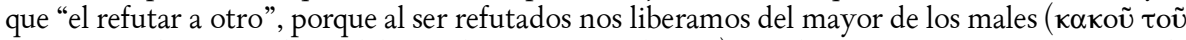
$\mu \varepsilon \gamma$ íctov; adviértase el uso del superlativo y véase la n. 6), puede parecer un cierto egoísmo de su parte, pero tiene que ser entendido en su justo sentido: liberarnos del mayor de los males (sc. "creer saber lo que en realidad no sabemos") constituye el primer paso seguro en el camino filosófico hacia la verdad y es a partir de allí que podemos contribuir a que otros hagan lo mismo. Si uno no se dejara liberar de las rígidas ataduras de la presunción de saber, difícilmente sería capaz de ayudar a otros.

${ }^{25}$ Cf. Pl. Sph. $230 \mathrm{c} 3$. 
Ahora bien, como dije más arriba, Teeteto no se sorprende en absoluto ante las palabras del Extranjero. El amansarse después de haber sido avergonzado es para él "la mejor y más sensata de todas las predisposiciones" (230d5). ¿Acaso no es ésta una muestra del carácter manso del joven? A una respuesta afirmativa nos llevaría la parte final del diálogo que lleva su nombre y que precede al Sofista. Allí, en el último párrafo de la conversación (Tht. 210b11-c4), Sócrates revela el fruto que, según él, ha de producir en Teeteto el ejercicio mayéutico al cual acaba de someterse: si en alguna oportunidad el joven llegara a concebir algún conocimiento, éste sería mejor gracias a todo lo que se ha dicho en la actual conversación (todo el diálogo Teeteto); pero si resultara estéril y no lograra concebir nada, al menos no se mostraría tan pesado para aquellos con los cuales se reuniera a dialogar, sino más manso

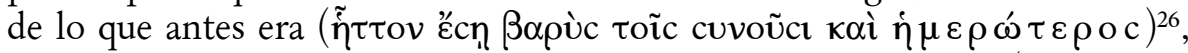

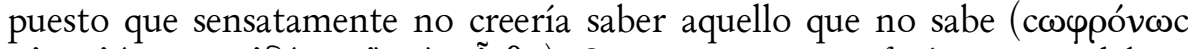

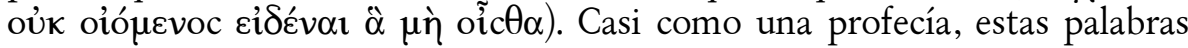
de Sócrates nos anticipan la buena disposición para dialogar que mostrará Teeteto en el Sofista, su actitud genuinamente filosófica. No resulta extraño, pues, que al inicio de nuestro diálogo sea el propio Sócrates quien recomiende al Extranjero elegir a Teeteto como su interlocutor, ya que responderá dócilmente $(\pi \rho \alpha \alpha \omega c)$ a sus preguntas ${ }^{27}$. Pero, no sólo el joven matemático muestra tal actitud en el diálogo, sino también su maestro, el filósofo de Elea. Así, en una conversación imaginaria con los que en otro tiempo trataron la cuestión del 'Ser', ambos se dirigen a ellos y piden: "en primer lugar, enseñadnos entonces qué queréis decir cuando pronunciáis 'ser', para que no

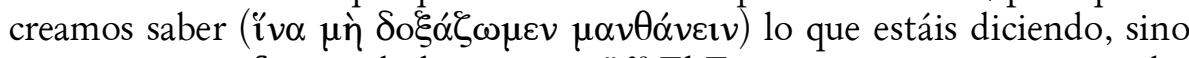
para que se verifique todo lo contrario". ${ }^{28}$ El Extranjero, pues, no quiere dar por supuesto qué significa 'ser' para los filósofos que le han precedido y por esa razón pide que le expliquen, dialogando, qué es lo que ellos mismos sostienen que es, a fin de no creer saber algo que en realidad no sabe.

Estando así las cosas, si el interlocutor del Extranjero es uno admirablemente sensato, alguien podría objetar entonces que en la conversación del Sofista no tiene lugar un ع̋ $\lambda \varepsilon \ngtr X O c$ filosófico como el descripto en la sexta definición. Por lo que he argumentado anteriormente, no hay dudas de que Teeteto no necesita ser sometido a la vergüenza de sí mismo, consciente como es de su

26 "No ser pesado" podría entenderse como sinónimo de "no ser hostil". Tal actitud, la de ser pesado o irritarse en el diálogo, es opuesta a la mansedumbre del filósofo. Véase, por ejemplo, el caso paradigmático de Trasímaco en la República y su mala disposición en el diálogo con

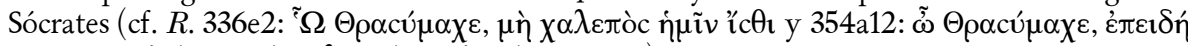

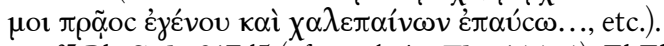

${ }^{27}$ Pl. Sph. 217 d5 (cf. también Tht. 144a4). El Eleata había propuesto encarar la definición del sofista por el camino del diálogo sólo si su interlocutor se dejaba llevar fácilmente y no

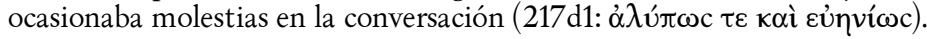

${ }^{28} \mathrm{Pl}$. Sph. 244a ss. 
propia ignorancia ${ }^{29}$. Con todo, esto aún no echaría por tierra mi hipótesis de que el Eleata, verdadero filósofo, sea presentado por Platón como practicante del método de la purificación. Un precioso testimonio de ello encontramos más adelante en $246 a 4$ ss., en el famoso pasaje de la "Gigantomaquia". Como lo explica el Extranjero, hay una lucha eterna de titanes en torno a la discusión del problema del 'Ser' y dos son los bandos que se oponen, casi sin reconciliación. Por una parte, están los "materialistas", aquellos que sostienen que sólo existe lo que se puede tocar y ofrece resistencia al tacto, afirmando que el 'Ser' es lo mismo que el cuerpo. Si alguien se atreve a decirles que existe algo que no tiene cuerpo, entonces lo desprecian totalmente y ya no quieren oír más nada sobre el asunto ${ }^{30}$. Por otra parte, está el grupo de los "idealistas" para quienes la verdadera realidad consiste en formas inteligibles que no tienen cuerpo. La diferencia entre estos dos grupos salta a la vista, pero resulta importante destacar que tal diferencia, que tiene que ver con una determinada concepción filosófica del mundo, se ve reflejada también en cómo ambos se muestran en el trato para con los demás: los "amigos de las Ideas”, dice el Extranjero, son más mansos ( férreos defensores de lo corpóreo ${ }^{31}$. De esta manera, si hubiera que recibir de estos grupos el lógos acerca del 'Ser', sería más fácil hacerlo de parte de los "idealistas", mientras que sería muy difícil y hasta casi imposible de parte de los "materialistas" (246c8). No obstante, el Eleata parece no resignarse ante la adversidad y por afán de hacer avanzar la discusión busca una forma de proceder con aquellos intratables, el único recurso posible para que quieran

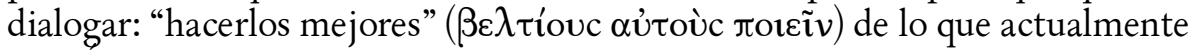
son. Optimo sería que efectivamente o de hecho se volvieran mejores, pero si esto ahora no es posible, al menos hay que intentar mejorarlos de palabra, en y con el diálogo. Sólo de esa manera será posible entablar con ellos una conversación y llegar a un acuerdo mutuo, lo cual es muy importante, puesto que, como dice el Extranjero, el acuerdo que se da entre los "mejores" es

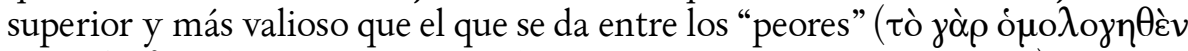

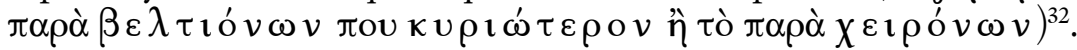

Esta última reflexión, que parece no tener importancia, se llena de sentido a la luz de lo dicho en la descripción del é $\lambda \varepsilon \ngtr \chi$ oc purificador. Según lo veo,

${ }^{29}$ Así Szlezák, Das Bild, 143, y también M. Frede, "The Literary Form of the Sophist", en Ch. Gill and M. M. McCabe, eds., Form and Argument in Late Plato, Oxford 1996, 138.

${ }^{30} \mathrm{El}$ "no querer escuchar" y el "menosprecio" que el interlocutor puede manifestar en la conversación son factores negativos que dificultan e incluso impiden que tenga lugar la conversación dialéctica tal cual la entendía Platón.

${ }^{31}$ En 248b7, el Extranjero confiesa estar más familiarizado con los "idealistas" (él es de alguna manera un "amigo de las Ideas") y de este hecho se puede inferir en consecuencia lo "manso" de su carácter.

${ }^{32}$ Las palabras utilizadas aquí nos remiten directamente a la descripción del ह̌ $\lambda \varepsilon \ngtr \chi O c$ en

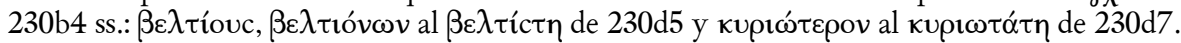


en este preciso momento de la conversación el Eleata estaría llevando a cabo un acto de purificación, al separar con su palabra lo "peor" de lo "mejor" 33 , al quitar de los materialistas su dureza y mejorarlos para la conversación. Que esto es así, viene confirmado un poco más adelante, en 247b1-247c7, cuando le pregunta a Teeteto qué piensan los "materialistas" que son aquellas cosas que creemos que existen y son incorpóreas como la justicia, la inteligencia y demás. Teeteto, que hace las veces de intérprete de aquellos, contesta que ahora se sienten verdaderamente "avergonzados" ( $\alpha \boldsymbol{i} c \chi \underline{v} v$ o $v \tau \alpha \mathbf{\imath})$ y que ya no se atreven a negar la existencia de tales cosas ni afirmar su corporeidad. A lo que el Extranjero, admirado, dice: "es evidente, Teeteto, que estos hombres se nos han mejorado ( $\dot{\eta} \mu \tilde{\imath} v \beta \varepsilon \lambda \tau$ íovc $\beta \varepsilon \gamma o ́ v \alpha c \imath v)$, porque antes

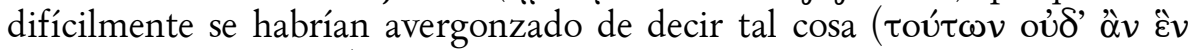
$\varepsilon \dot{\varepsilon} \alpha \boldsymbol{\imath} \mathrm{c} \chi v \boldsymbol{v} \theta \varepsilon \tilde{\mathbf{\imath}} \varepsilon v . .$.$) ". Ahora, en cambio, una vez que han sido sometidos a$ la purificación que avergüenza ${ }^{34}$, se ven llevados por la fuerza del argumento a dejar abierta al menos una pequeña posibilidad de que exista algo incorpóreo (247d1) y ello no significa otra cosa más que un "mejoramiento" en la discusión: los intratables se han vuelto más "mansos" por efecto del élenkhos purificador del Eleata.

\section{EL FILÓSOFO SILENCIADO}

Hacia la última parte de nuestro pasaje nos enfrentamos con importantes dificultades de interpretación. El texto aquí es sumamente ambiguo y el lector tiene que estar más atento que nunca. No es casual, pues, que en un mismo párrafo aparezcan dos expresiones del lenguaje militar que nos exhorten precisamente a "montar guardia". Las mayores dificultades las encontramos

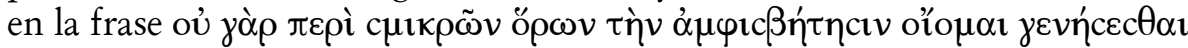

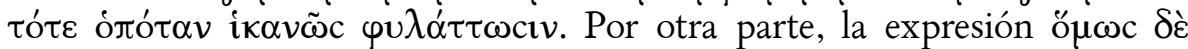
ह́c $\tau \omega c \alpha \nu^{35}$ con la cual el Extranjero deja que por el momento sean los sofistas los practicantes del $\check{\varepsilon} \lambda \varepsilon \gamma \chi X \mathrm{Oc}$, es generalmente descuidada por los comentaristas y hasta aquí nadie se ha preguntado por su verdadero valor dentro del contexto en el que aparece. A mi juicio, si se aceptan ciertos presupuestos, tendríamos

${ }^{33} \mathrm{Pl}$. Sph. 226d2-10: "muchos dicen que separar lo peor de lo mejor...es una especia de

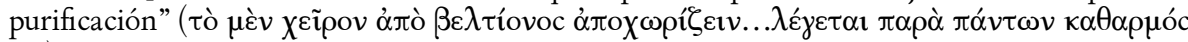

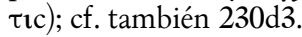

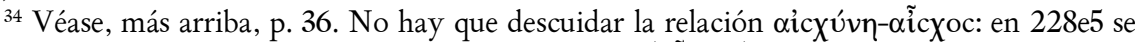
dice que la ignorancia es una especie de "deformidad" ( $\alpha$ ĩc Xoc) y ello nos remite a 230e 2 , en donde el Eleata había admitido con gran énfasis que aquel que no se somete a la refutación es

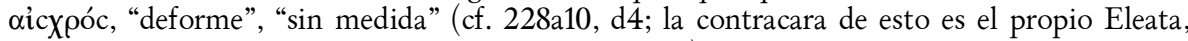
quien, según vimos en p. 34, es un hombre "medido"). De ahí se desprende que el someter al interlocutor a la vergüenza de sí mismo es poner de manifiesto su "deformidad", su "fealdad", en una palabra, "separar lo feo de lo bello": purificar.

${ }^{35}$ No veo razones convincentes para cambiar la lectura del manuscrito (ह̌c $\tau \omega c \alpha \nu$ por ěc $\tau \omega$ como hace Burnet), por lo que sigo en este punto la edición de E. A. Duke, Platonis Opera, Oxford 1995. 
allí la clave para comprender definitivamente la "presencia" del filósofo en la sexta definición. Sólo si asumimos que éste es el único merecedor del título de "purificador de almas" y no el sofista, podremos alcanzar entonces una mejor interpretación de todo el pasaje.

Y bien, después del ejemplo de las semejanzas entre el "perro" y el "lobo", el Extranjero afirma: "un hombre seguro tiene que estar siempre atento y más aún cuando se trata de semejanzas, porque el género del 'sofista' es uno de los más escurridizos". Estas palabras son una advertencia directa para Teeteto. En primera instancia, él tiene que estar seguro ahora y "montar guardia", porque de lo contrario será imposible atrapar al sofista. Pero, si uno espera aquí que el Eleata, como en otras partes del diálogo, dé una explicación de lo que ha dicho, cómo cree él que hay que montar guardia y prevenirse ante las semejanzas, se encuentra con que nada de eso sucede. Muy por el contrario, parece que el Extranjero no tiene ninguna intención de aclarar con mayor detalle la confusión de Teeteto y señalar de manera precisa el límite que separa al practicante (filósofo) del sofista. Es más, cuando el sexto intento de definición ha terminado y uno vuelve la mirada hacia este punto, da toda la impresión de que Platón deliberadamente dejó allí algo sin tratar: "de todos modos dejemos que sean ellos", puesto que "no habrá ninguna duda con respecto a límites tan finos, cuando uno esté lo suficientemente prevenido". Que sean los sofistas los nobles purificadores del alma, sólo es aceptado por el Extranjero en la medida en que más tarde, "la discusión ya no girará en torno a límites tan finos como los que hay ahora entre el perro y el lobo, porque estaremos más seguros en lo que se refiere a las semejanzas"36. En el momento actual de la conversación no hay una prevención suficiente contra

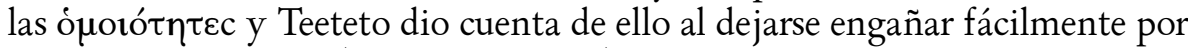

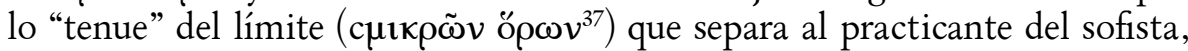
al perro del lobo. Si bien uno es lo más manso y el otro lo más salvaje, si bien uno habita la región más luminosa del 'Ser' y el otro la oscuridad del 'No-Ser' -todo lo cual nos haría pensar en que el "límite" entre ellos es en realidad muy grande- no debemos perder de vista el hecho de que ambos son "dos caras de la misma moneda” y que donde está uno, se encuentra el otro ${ }^{38}$.

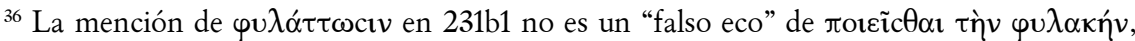
como sostuvo L. Campbell, The Sophistes and Politicus of Plato with a Revised Text and English Notes, Oxford 1867, 61, sino que una expresión remite a la otra. En este sentido me veo más inclinado a aceptar la propuesta de Kerferd, "Plato's Noble Art", 86, de que el sujeto

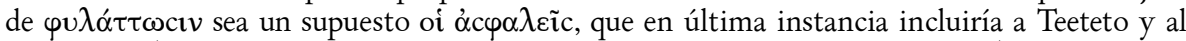
Extranjero (de ahí, quizás, la corrección $\varphi v \lambda \alpha ́ \tau \tau \omega \mu \varepsilon v$ propuesta por M. Schanz).

${ }^{37}$ Entiendo y traduzco aquí öpoc por su primer sentido o acepción de "límite", "frontera", "línea que separa o divide", aunque no deberíamos perder de vista el hecho de que todo el diálogo es un intento de "definición" del sofista por medio del lógos.

${ }^{38}$ En $253 \mathrm{c} 9$, mientras se busca al sofista, el filósofo es el que se aparece primero. Cf. Notomi, The Unity, 71-3. Para la íntima relación filósofo-sofista y el problema de la definición de ambos, véase 250e5-251a3. Como bien lo expresó Movia, Apparenze, 307: "la ricerca di ciò 
De acuerdo con esta lectura, creo que sería más conveniente entender entonces la negación oủ como modificador del verbo yevńcec $\theta \alpha \iota$ y no tanto

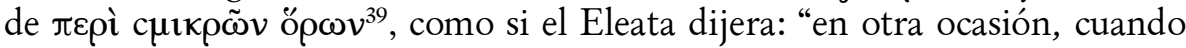
estemos bien prevenidos contra las semejanzas, no vamos a tener ninguna duda ${ }^{40}$, si se nos presenta un caso tan fino de definición como el que se ha dado ahora entre el perro y el lobo, entre el filósofo y el sofista". Que en este punto hay dudas, lo dejará por sentado el propio Eleata cuando más adelante haga un repaso por las seis definiciones y diga de la última: "en cuanto a la sexta, si bien es discutible, le concedimos de todos modos que fuera él (sc. el sofista) un purificador de las opiniones que son un impedimento para que el

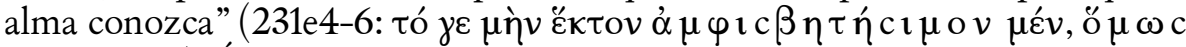
$\delta$ ' $̋ \theta \varepsilon \mu \varepsilon v . .$.$) . Éste es un testimonio más que evidente de que la equiparación$ "practicante=sofista" en absoluto ha convencido al Extranjero. Además, si la sexta definición tuviera algo que ver con el sofista, debería haber al menos alguna mención del arte de la purificación en el cierre del diálogo, cuando finalmente se lo ha capturado en su verdadera naturaleza engañosa (268c8-d4). ¿Por qué razón, entonces, el Eleata no desarrolla con Teeteto la distinción entre el practicante y el sofista? ¿Por qué no establece la sexta como una definición más de este último, despejando toda duda? La única respuesta plausible y que, según creo, haría justicia a la evidencia del texto es la que intento defender aquí: la sexta definición tiene que ver más con el filósofo y no con el sofista.

Como lo he mencionado más arriba, en la sexta definición, que podríamos considerar la primera "aparición" del filósofo, Platón nos lo presenta con una de sus herramientas, la más básica o elemental: el '̌̉ $\varepsilon_{\chi X X}$ oc. Más adelante,

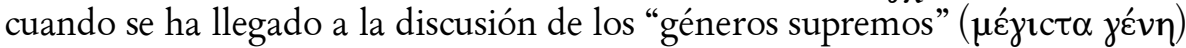
en un nivel de argumentación más elevado y difícil, el filósofo reaparece pero con su arma más poderosa, la dialéctica, aclamada como "la más grande de

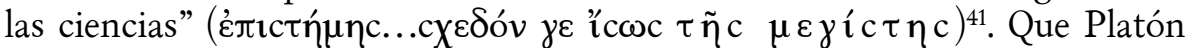
habría pretendido que asociemos a este filósofo dialéctico con el practicante

che è la sapienza apparente (sofistica) è inseparabile dalla ricerca di ciò che è la sapienza vera (la filosofia), come la conoscenza dell' apparire o non-essere è inseparabile da quella dell' essere".

${ }^{39}$ Kerferd, "Plato's Noble Art", 86-7, construye la negación oủ con el verbo oľou Contrariamente, Trevaskis, "The Sophistry of Noble Lineage", 38-9, N. B. Booth, "Plato, Sophist 231 a, etc.”, CQ 6.1-2, 1956, 89-90, y Giannopoulou, "The Sophistry”, 117, n. 61, quienes prefieren entenderlo como modificador de c $\mu \iota \kappa \rho \tilde{\omega} v$ ő $\rho \omega v$. Según lo alcanzo a entender,

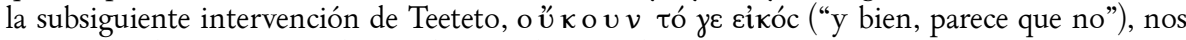

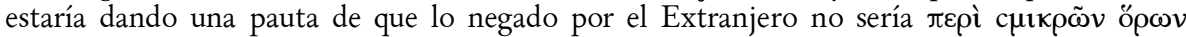

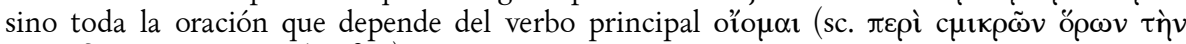

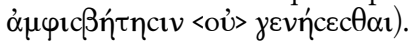

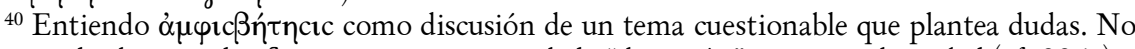
hay que olvidar que el sofista es uno que gusta de la "discusión" o contienda verbal (cf. 226a).

${ }^{41} \mathrm{Pl}$. Sph. 253c5. Adviértase el uso del superlativo $\mu \varepsilon \gamma$ zíctqc y su relación con las palabras empleadas en la descripción del método de la purificación. 
de la sexta definición, podría estar sugerido, quizás, cuando le hace afirmar al Eleata que esta ciencia dialéctica no pertenece a ningún otro más que a quien

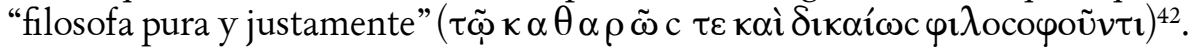
Tales palabras vuelven nuestra mirada otra vez hacia la propia figura del Extranjero: él mismo, que hasta este momento, según hemos visto, podría ser considerado como purificador, es caracterizado también como filósofo dialéctico, capaz de mostrar a su joven interlocutor qué géneros concuerdan entre sí, cuáles se dejan mezclar y cuáles no ${ }^{43}$. Ahora bien, así como en el caso del practicante se deja de lado la cuestión de su verdadera identidad, también aquí, si bien se dice explícitamente que es el filósofo el que se sirve de la dialéctica, se deja abierta la posibilidad de seguir indagando sobre él, de encontrarlo en ese lugar, "ahora o más tarde, si es que lo buscamos" o "queremos" $(253 \mathrm{e} 8,254 \mathrm{b3})$.

Estas últimas declaraciones, según lo advirtió hace tiempo H. J. Krämer, pueden ser consideradas, dentro del nuevo paradigma hermenéutico de Platón iniciado por la "escuela de Tübingen", como situaciones típicas de los diálogos en donde el texto parece sugerir que la propia naturaleza de aquello de lo cual se está hablando exige dejar de lado la cuestión y retomarla, tal vez, en otra ocasión. Son los así llamados "pasajes de silenciamiento" u "omisión" (Aussparungsstellen), que rozan siempre problemas fundamentales o de mayor importancia y valor para la filosofía platónica, como lo son los principios del Ser, del Bien y de la estructura matemática del mundo material, y que, dadas sus características esenciales, no pueden ser tratados por escrito sino sólo aludidos en el texto y reservados para la oralidad del diálogo vivo ${ }^{44}$. Más allá de lo discutido que puedan resultar las asunciones de este nuevo paradigma, creo que nuestro pasaje de Sofista 230e5-231b8 podría iluminarse y ganar mayor claridad en la interpretación, si lo leemos a la luz de las consideraciones del estudioso alemán. Que la última parte de la sexta definición también podría ser considerada como un lugar de silenciamiento u omisión, quizás esté sugerido por la dimensión temporal "ahora-después" presente en todo el párrafo, especialmente en el $\tau \grave{\alpha} v \tilde{v} v$ de 231a4, en el uso

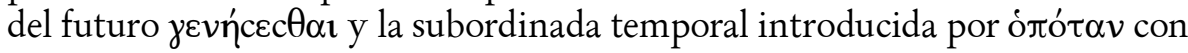

${ }^{42} \mathrm{Pl}$. Sph. 235e5. El uso aquí de $\delta$ iкaíwc nos remite al pasaje de Tht. 167e3, en donde se dice que sólo el que dialoga con seriedad hace justicia en los lógoi; el injusto, en cambio, es el que bromea y busca competir para vencer a su interlocutor, esto es, el sofista.

${ }^{43}$ Como lo advierte el Teeteto, nuestro extranjero puede hablar de "una idea muy amplia,

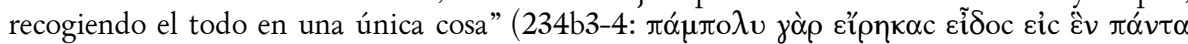
cu $\lambda \lambda \alpha(\beta \omega \dot{v})$ ); él es uno de esos que llevan a cabo una "búsqueda según cada cosa en particular

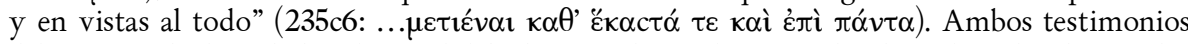
deberían ser leídos a la luz de aquel difícil pasaje de $253 \mathrm{~d} 5$ ss., en donde se describe el proceder del verdadero dialéctico.

${ }^{44}$ H. J. Krämer, Arete bei Platon und Aristoteles. Zum Wesen und zur Geschichte der platonischen Ontologie, Heidelberg 1959, 24 y 390-2. Cf. también Szlezák, Platon, 324 y, del mismo, Leer, 33-35. 


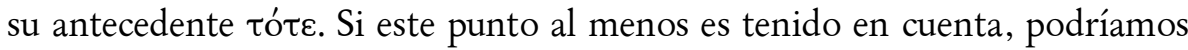
suponer entonces que Platón habría considerado la posibilidad de tratar en algún momento, de manera exhaustiva y suficiente, la cuestión de las semejanzas entre el perro y el lobo, entre el filósofo y el sofista ${ }^{45}$, pero, por las razones aducidas en las páginas finales del Fedro, deliberadamente ello no fue puesto por escrito. En efecto, todo lo que tiene que ver con la filosofía representa para Platón algo de "mayor valor" y necesariamente está reservado para la oralidad. Lo escrito sobre el filósofo en el Sofista no constituye, según lo entiendo, un tratamiento suficiente ni agota todo lo que aquél habría significado a los ojos de Platón, ni siquiera lo que leemos en otros diálogos ${ }^{46}$. Así, en la sexta definición, el filósofo de Atenas nos estaría advirtiendo sobre el hecho de que no vamos a encontrar un tratamiento acabado o "suficiente" que nos permita dilucidar en qué se asemejan y diferencian los filósofos-perros de los sofistas-lobos, porque distinguir uno del otro significaría definirlos y mientras que la definición de uno sí puede llevarse a cabo, la del otro, la del filósofo, implicaría un mayor esfuerzo para adentrarnos en su morada, en aquella luminosa región que habita y que la mayoría de las personas no puede contemplar. El Eleata calla deliberadamente sobre este punto ${ }^{47}$, porque aclarar la diferencia entre el filósofo y el sofista habría exigido acabar en ese preciso momento con el objetivo primero del diálogo (sc. definir al sofista), y tomar otra dirección, otro camino que posiblemente Teeteto, bajo los presupuestos

${ }^{45}$ Así lo entiende Trevaskis, "The Sophystry of Noble Lineage", 38-9: "The reason for not making the distinction is not that it is of great importance, but that it is not felt opportune

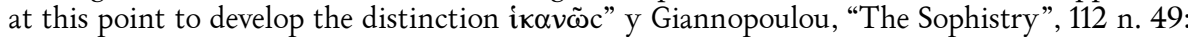
"...the Stranger seems to be suggesting that a 'real' definition is possible only when there is

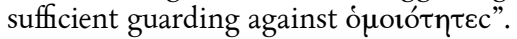

${ }^{46}$ Yo no creo, como sostiene Frede, "The Literary Form”, 149-50, y también muchos otros, que no hace falta pensar en un posible tratamiento del Filósofo, puesto que ya en el Sofista, como también en el Teeteto y en el Político, está todo lo que tiene que ver con él (“....we did not really need a further dialogue, the Philosopher, to tell us what the philosopher is. We need to read the Theaetetus, the Sophist, and the Politicus to find out how at least Plato conceives of the philosopher. These dialogues are his answer to the question what the philosopher is"). Frede considera si es necesario o no esperar un tratamiento "por escrito" del Filósofo y en eso pierde el punto central de la cuestión. La promesa platónica de una investigación sobre el Filósofo no tiene que ser entendida en términos de una "investigación por escrito". Platón nunca tuvo la intención de escribir sobre las cuestiones "más importantes" -los Primeros Principios de su filosofía (cf. Ep. 7.341c5)- y, sobre la base de lo que él mismo manifiesta en las últimas páginas del Fedro, queda claro cuáles son las razones de ello. Lo que el ateniense parece sugerir más bien es que la definición del Filósofo ha de seguir a la del Sofista y a la del Político, pero en otra dimensión, en la oralidad del diálogo vivo, puesto que la escritura nunca garantiza un grado

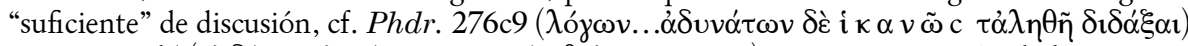

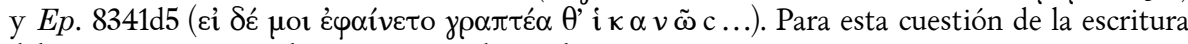
del Filósofo, remito a los autores citados en la n. 8 .

${ }^{47}$ Para el motivo de la "reserva del saber" (Zurückhaltung des Wissens) en la "transmisión" del conocimiento y su relación con las capacidades del interlocutor, véase Szlezák, Platon, 1, 54 y passim y, del mismo, Leer, 31 ss., 43 y 92 ss. 
actuales de la conversación, no habría podido seguir, pero fundamentalmente habría significado para Platón la obligación de abandonar el escrito para pasar a la discusión oral del diálogo vivo.

Un indicio de esta instancia oral de discusión sobre el filósofo incluso nos es dado en la escritura del Sofista. Si el Extranjero fue capaz de llamar la atención sobre la cuestión de las semejanzas y advertir a su inexperto interlocutor para que esté atento y no se deje engañar, probablemente ello quiere decir que él mismo ya ha advertido en otra ocasión la dificultad del asunto y que ahora está lo suficientemente prevenido y atento. De él se dijo al comienzo del diálogo que había oído hablar "suficientemente" sobre la distinción entre el sofista, el político y el filósofo y que no se había olvidado

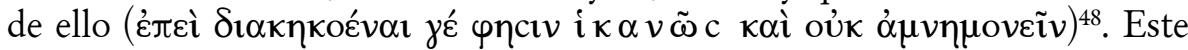
"haber oído suficientemente" nos remite a una dimensión oral de enseñanza en Elea, en el círculo íntimo de los amigos de Parménides y Zenón ${ }^{49}$. El grado suficiente de lo que él mismo ha oído y aún recuerda sobre la distinción de géneros lo ubica, junto al círculo eleata, en aquel contexto de "transmisión" del conocimiento en el diálogo vivo sobre el cual versan los párrafos finales del Fedro. Él es un verdadero dialéctico, que no sólo conoce y domina el tema en torno al cual gira la conversación, sino que también elige un alma adecuada para "darlo" a conocer, la de Teeteto (cf. 265d8); él es capaz de venir en auxilio de lo que ha oído y, fundamentalmente, sabe cuándo tiene que hablar y cuándo callar ${ }^{50}$ : la expresión ö $\mu \omega c \delta \varepsilon$ éct $\omega c \alpha \nu$, como creo, daría cuenta de ello. En fin, la situación de diálogo actual entre el Extranjero y Teeteto podría ser considerada como un momento dentro de una enseñanza oral más extensa ${ }^{51}$. El contraste entre ésta y una enseñanza escrita se ve sobre todo en los frutos que una y otra produce. La escritura, como leemos en el Fedro, procura a los que aprenden sólo la creencia de sabiduría (copíac $\delta o ́ \xi \alpha v)$ y no la verdad. En efecto, después de oír muchas cosas, sin una enseñanza oral adecuada (’’vev

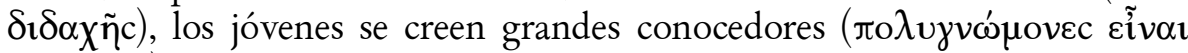

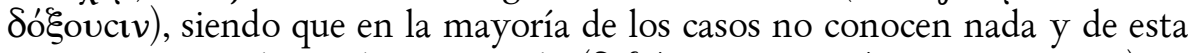

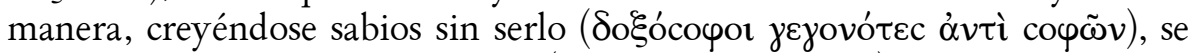
vuelven personas difíciles de $\operatorname{tratar}(\chi \alpha \lambda \varepsilon \pi \text { o ì cuveĩv } \alpha \mathbf{l})^{52}$. Teeteto, como ya hemos visto, sólo cree saber lo que sabe y nada más que eso. Además, y como consecuencia de esa actitud propia de un filósofo, se muestra muy amigable para con el Extranjero y no causa ninguna molestia en la conversación: él es manso.

\footnotetext{
${ }^{48}$ Sph. 217b7. Véase Szlezák, Das Bild, 134.

${ }^{49} \mathrm{Cf}$. Reale, Per una nuova interpretazione, 431.

${ }^{50} \mathrm{Pl}$. Phdr. 276a5-7.

${ }^{51}$ Recuérdese que el Eleata ya ha frecuentado a Teeteto en otra ocasión, cf. 218a2.

${ }^{52} \mathrm{Pl}$. Phdr.274e5-275b2; cf. Sph. 251c2-5.
} 
CONClUSión: "LA SOFÍSTICA DE NOBLE LINAJE", VERDADERA FILOSOFÍA.

Cuando finalmente se ha alcanzado la definición que caracteriza al sofista en su verdadera naturaleza de fabricador de ilusiones y engaños por medio de discursos, el Extranjero, citando a Homero, exclama: "de este linaje y sangre"

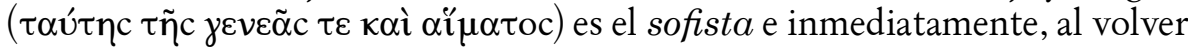
desde aquí la mirada hacia la sexta definición, uno podría completar en su pensamiento: "y no de aquel otro noble linaje" ${ }^{53}$. Los elementos positivos que aparecen en ella hicieron que el Extranjero no se conformara con llamar simplemente "sofística" al método catártico del élenkhos, sino que lo llevaron a mejorarla, en un acto de purificación, con el título de "noble". Platón claramente reconoció en el arte de sus contrincantes un uso justo de los argumentos, uno orientado hacia la verdadera búsqueda de la sabiduría ${ }^{54}$,

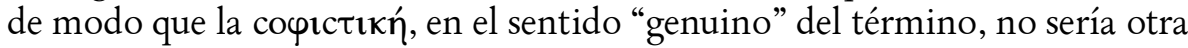
cosa más que un sinónimo de $\varphi$ i $\lambda$ ocọía.

Así pues, a lolargo dela conversación del Sofista y sobre la base de los indicios textuales que hasta aquí he recabado, creo que uno estaría en condiciones de considerar al anónimo Extranjero de Elea como un "sofista de noble linaje", practicante del élenkhos purificador. A mi parecer, la confrontación directa con el eleatismo por parte de Platón, que lo obligó a transgredir los preceptos del gran Parménides y con ello alcanzar para sí el máximo logro filosófico (la cuestión del "No-Ser" como diferencia y el problema de la combinación de los "géneros supremos"), hizo que terminara por adoptar en la escritura de su enfrentamiento y asunción de la filosofía parmenídea una determinada

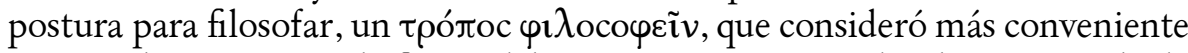
encarnarlo esta vez en la figura del anónimo extranjero de Elea y no en la de Sócrates. Quizás, el hecho de que éste "hubiera destruido" el mandato del gran Parménides, podría haber sido visto como un injusto acto de enemistad o "disputa", siendo que el "padre" de aquella doctrina ya no podría defenderse.

${ }^{53}$ Pl. Sph. 231b8. Que el cierre del diálogo y su definición del sofista nos remiten directamente a la sexta definición, queda claro también por las últimas palabras del Eleata en $268 \mathrm{~d} 3$ ss.: “...quien diga que realmente de este linaje y sangre es el sofista, diría...la más pura

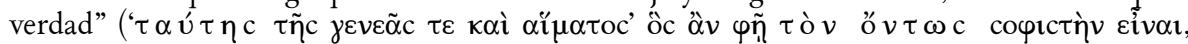
$\tau \dot{\alpha} \lambda \eta \theta \dot{\varepsilon} \mathrm{c} \tau \alpha \tau \alpha \ldots . \dot{\varepsilon} \rho \varepsilon \tilde{\mathbf{i}}$ ), que retoman aquellas de Teeteto en 231c ss.: "por todas las cosas que se nos han mostrado, yo al menos no sé qué hay que decir, si se pretende decir la verdad, sobre

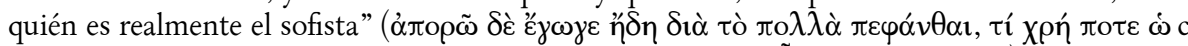

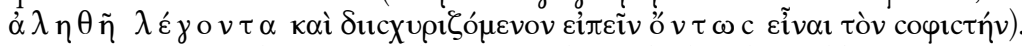

${ }^{54}$ En este sentido, creo que la opinión de Kerferd, “The Noble Art”, 84, es correcta: “... Plato was aware that one aspect of their (sc. sophists) activities was not only extremely valuable but was a necessary preliminary to his own philosophy". Tanto el sofista como el

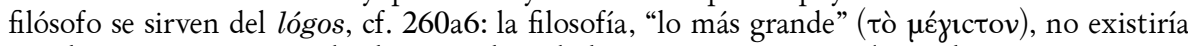
sin el lógos. En esto reside el punto clave de la semejanza entre ambos y la importancia que tenía para Platón distinguir uno del otro. Para la problemática de la asunción y confrontación de Platón con la sofística, puede verse la primera parte, "Logos Protreptikos", del trabajo de K. Gaiser, Protreptik und Paränese bei Platon. Untersuchungen zur Form des Platonischen Dialogs, Stuttgart 1959. 
La única manera, la más amable, que Platón pudo haber encontrado, fue la introducción de este Extranjero, íntimo amigo del círculo eleata, conocedor cercano de su pensamiento y al mismo tiempo tan cercano al propio Sócrates en su trato benévolo y manso del lógos. 